\title{
Letrōnica
}

\section{O subjuntivo não é apenas o modo da incerteza}

\section{Subjunctive is not only the uncertainty mode}

Tatiana Schwochow Pimpão ${ }^{1}$

Doutora em Linguística pela Universidade Federal de Santa Catarina em 2012. Desde 2005, trabalha na Universidade Federal do Rio Grande, atuando nos cursos de Letras e no curso de Especializaçâa em Linguistica e Ensino de Lingua Portuguesa. Nesta universidade, coordena dois grupos de estudos: Grupo de Estudos Dialetológicos Funcionalismo Lingústico de Orientação Givonian (GEFLOG).

E-mail: tatianapimpao@furg.br
RESUMO: Tendo como referência pesquisas sociolinguísticas conduzidas com dados do português do Brasil, a proposta deste artigo é apresentar evidências de que o subjuntivo não pode ser considerado estritamente o modo da incerteza, conforme preveem as gramáticas normativas. Resultados desses estudos põem em destaque duas situações diversas: (i) o uso do subjuntivo em contexto de projeção futura, e somente por conseguinte um contexto de incerteza; e (ii) o uso do subjuntivo em contexto de certeza, especialmente sob o escopo de determinados conectores das orações adverbiais causais e concessivas. Pressupostos da Linguística Funcional, como a associação do subjuntivo à projeção futura (GIVÓN, 1995) e o uso desse modo verbal como modo subordinante (BYBEE; PERKINS; PAGLIUCA, 1994) amparam os resultados das pesquisas sociolinguísticas.

Palavras-CHAVE: Subjuntivo; Sociolinguística; Projeção futura.

ABSTRACT: Based on sociolinguistic researches conducted with Brazilian Portuguese data, the aim of this paper is to present evidence that the subjunctive can not be directly considered the uncertainty mode, as predict by the normative Brazilian grammars. Results of these studies highlight two different situations: (i) the use of subjunctive in the context of future projection; and (ii) the use of subjunctive in the contexto of certainty, specifically within the scope of certain connectors of the causal and concessive adverbial clauses. Principles from Functional Linguistics, like the subjunctive association to future projection (GIVÓN, 1995) and the use of subjunctive as a subordinate mood (BYBEE; PERKINS; PAGLIUCA, 1994) support the results of sociolinguistics researches.

KEYWORDS: Subjunctive; Sociolinguistics; Future projection 


\section{Primeiras palavras}

A gramáticas normativas estabelecem uma nítida diferença entre

a concepção do modo subjuntivo e do modo indicativo mediante a atribuição de valores distintos expressos na e pela morfologia verbal. De forma geral, ao modo subjuntivo são associadas noções de incerteza e de dúvida; ao indicativo, por oposição, noções de certeza e de realidade (BECHARA, 2006; CEGALLA, 2007; CUNHA; CINTRA, 2007). Sob esse ponto de vista, o morfema de modo (morfema modo-temporal na concepção da gramática normativa) imprime noções de modalidade.

Diferentemente da prescrição da gramática tradicional, resultados de pesquisas sociolinguísticas ${ }^{1}$ de orientação laboviana têm demonstrado a sensibilidade do uso do modo subjuntivo a contextos de projeção futura (PIMPÃO, 1999; MEIRA, 2006; CARVALHO, 2007; ALMEIDA, 2010; PIMPÃO, 2012), bem como seu emprego em contextos de pressuposição, mais próximo à certeza (PIMPÃO, 1999; ALMEIDA, 2010; PIMPÃO, 2012). Esses estudos sinalizam dois pontos: (i) o uso do modo subjuntivo em contextos de projeção futura, colocando em evidência o aspecto temporal, e só secundariamente o modal de incerteza; (ii) a presença desse modo verbal em contextos próximo à certeza.

O objetivo deste artigo centra-se em, portanto, apresentar evidências de que o subjuntivo não é estritamente o modo da incerteza; antes, é o modo da projeção futura (PIMPÃO, 1999; MEIRA, 2006; CARVALHO, 2007; ALMEIDA, 2010; PIMPÃO, 2012) e, em alguns casos (determinadas orações concessivas e orações causais), o modo subordinante, sendo usado em contextos de pressuposição, que se aproximam de uma situação considerada real, certa (CÂMARA JR., 1979, 1986; PERINI, 1996; PIMPÃO, 1999; PERINI,

1 Essas pesquisas estão apresentadas na seção 4 deste artigo.
2006; ALMEIDA, 2010; PIMPÃO, 2012). Pesquisas sociolinguísticas apontam, primeiramente, um uso variável do modo subjuntivo, que cede espaço ao modo indicativo; e, portanto, em segundo lugar, uma distribuição na língua distinta da apontada pelas gramáticas normativas.

Inicialmente, este artigo apresenta, nas duas primeiras seções, a perspectiva das gramáticas normativas e a perspectiva dos linguistas acerca do modo subjuntivo. Na seção quatro, são destacados alguns estudos que trataram do uso variável do subjuntivo a partir de dados do português brasileiro. A quinta seção traz evidências da relação entre modo subjuntivo e projeção futura, seguida das palavras finais.

\section{0 que dizem as gramáticas}

As gramáticas normativas do português brasileiro apresentam uma relativa uniformidade com relação à conceituação de modo subjuntivo e à descrição de seu emprego, tendo como base explanatória oposições nocionais entre subjuntivo e indicativo. Se ao indicativo são associadas atitudes de certeza, de realidade; ao subjuntivo são atribuídas atitudes opostas, conforme se observa, a título de ilustração, nesta passagem de Cunha e Cintra (2007, p. 479): "Ao empregarmos o MODO SUBJUNTIVO, é completamente diversa a nossa atitude. Encaramos, então, a existência ou não existência do fato como uma coisa incerta, duvidosa, eventual, ou, mesmo, irreal ${ }^{2 \prime}$.

Um panorama interessante e distinto é apresentado pelas primeiras gramáticas. Na obra de Barros (1957 [1540]), no modo indicativo, modo para demonstrar, a morfologia de tempo presente do indicativo equivale ao presente que utilizamos no português atualmente. Por outro lado, o presente do subjuntivo do português atual está, na referida obra, diluído em dois

${ }^{2}$ Cunha (1992) apresenta a mesma definição para o modo subjuntivo. 
modos verbais: o outativo, modo para desejar, e o subjuntivo, modo para ajuntar. Vale destacar que o modo para desejar projeta uma determinada situação para o futuro.

Esse valor de futuridade marca presença na obra de Barros (1957 [1540]): no modo outativo, a morfologia flexional do presente do modo subjuntivo atual está classificada como futuro, denominado, conforme palavras de Barros (1957 [1540], p. 33-34), "tempo vindouro"; e, no modo subjuntivo, o presente de hoje está classificado igualmente como presente (cf. PIMPÃO, 2009).

Barboza (1830), ao tratar do presente imperfeito, estabelece uma comparação interessante com Barros (1957 [1540]), conforme ilustra a seguinte passagem:

As Linguagens 'Seja, Haja de ser, Esteja sendo' são do tempo presente nestas orações: 'Estimo que sejas o que és': = Estimo que estejas gozando da companhia dos teus': = Espero que teus serviços hajão agora de ser premiados'. Porêm as mesmas Linguagens parecem do futuro nestes lugares de João de Barros (BARBOZA, 1830, p. 223).

É possível perceber uma correlação entre presente e futuro, que, segundo Barboza (1830, p. 224), é própria dos tempos imperfeitos ou não-acabados, "cujas existencias [sic] são continuadas sem determinação de fim".

Com base no exposto, importa destacar dois aspectos: (i) a forte associação entre a morfologia de modo verbal e a modalidade, promovida pelas gramáticas normativas (ainda que mencionem o termo modalidade, mas sim atitude) e (ii) a estreita relação, apontada nas primeiras gramáticas, entre o modo subjuntivo e valores temporais (morfologia de presente do subjuntivo ilustrativa do tempo vindouro/futuro). Essa relação entre a morfologia do modo subjuntivo e o tempo futuro mostra-se crucial na análise dos dados de variação no português brasileiro. Conforme será visto adiante, de forma geral, o uso do subjuntivo está associado a contextos de projeção futura.

\section{O que dizem os linguistas}

Pesquisadores com formação filológica e/ou linguística, por estarem mais atentos ao uso efetivo da língua em situações reais de comunicação, admitem a perda de valores associados à morfologia flexional do subjuntivo e a extensão desses valores para outras estratégias linguísticas, o que permite a expansão de uso do indicativo. Câmara Jr. (1979) reconhece o uso do modo subjuntivo em orações independentes, como ocorre com o item talvez, porém ressalta que a noção de dúvida é assinalada pelo advérbio, não pelo modo verbal.

Para Câmara Jr. (1986), o subjuntivo, no português, é como uma servidão gramatical $^{3}$, usado em certos tipos de frases:

em oração independente depois do advérbio de dúvida talvez; em oração integrante subordinada a verbos de significação volitiva ou optativa; em oração relativa, para expressar apenas a possibilidade de qualificação expressa; em orações subordinadas finais; em orações subordinadas concessivas (CÂMARA JR., 1986, p. 225-226).

Para o autor (1974), desponta, já no indo-europeu4, uma tendência para uma categoria morfológica esvaziada de valores nocionais. De forma alguma esse esvaziamento na morfologia flexional implica uma omissão da atitude do falante frente ao que enuncia; a atitude mantém-se, porém fora da estrutura mórfica. Em alguns casos, a dúvida, o desejo, a hipótese estão

\footnotetext{
${ }^{3}$ A noção de servidão gramatical também é mencionada em História e Estrutura da Língua Portuguesa (1979).
}

4 Câmara Jr. (1974) aponta a tendência à simplificação dos modos verbais na cultura ocidental moderna 
presentes mesmo com o indicativo: "Suponho que é verdade" (CÂMARA JR., 1979, p. 133). Por essa razão, "em todo o domínio indo-europeu, o modo que assim subsistiu, propendeu a tornar-se mais uma categoria sintática do que exclusivamente nocional, como índice de SUBORDINAÇÃO de uma frase a outra" (CÂMARA JR., 1974, p. 123 - grifo do autor).

Alinhado à posição assumida por Câmara Jr. $(1979,1986)$, Perini (1996, 2006) defende a tendência da oposição morfológica entre subjuntivo e indicativo tornar-se essencialmente formal, constituindo uma servidão gramatical, uma vez que o subjuntivo passa a depender de determinados verbos e itens, como o talvez. Essa reconfiguração pode conduzir à eliminação gradativa do próprio subjuntivo, em especial o uso do presente do subjuntivo (PERINI, 1996, 2010).

Perini (1996, p. 258) justifica seu posicionamento acerca da ausência de oposição modal entre subjuntivo e indicativo com base em exemplos em que a atitude de certeza se manifesta independentemente do modo verbal: “Tenho certeza de que Selma fuma e É trágico que Selma fume." Da mesma forma, os dois modos verbais podem expressar a falta de certeza: "Eu sonhei que Selma fumava cachimbo e Eu duvido que Selma fume cachimbo. (PERINI, 1996, p. 258).

Na esteira desses autores, Mattos e Silva (2006, p. 119) salienta que o subjuntivo, na passagem do latim para o português, em que também podia ocorrer em orações principais, "passa a ser sempre uma forma verbal própria de orações dependentes e selecionada a partir de características das frases em que se encaixa", sendo considerado, portanto, um padrão formal. Nessa perspectiva, portanto, a ausência de valores semânticos associados à morfologia do modo subjuntivo justifica-se pela característica desse modo ocorrer, preferencialmente, em orações subordinadas. Complementa, ainda, afirmando que, nas variedades faladas, o uso do indicativo supera o do subjuntivo, o que permite o uso variável do subjuntivo e indicativo.
A perda das distinções de modo também é considerada por SilvaCorvalán (1994) no estudo desenvolvido sobre o espanhol falado em Los Angeles. Destaca a possibilidade de o subjuntivo no espanhol tornar-se dependente de traços morfossintáticos e lexicais identificados no contexto.

O breve panorama apresentado nesta seção deixa explícito que conceber uma conceituação binária para subjuntivo e indicativo, a partir das noções de certeza e incerteza, realidade e irrealidade, como muito bem alerta Said Ali (1971, p. 324), "não basta para definir o emprêgo [sic] do subjuntivo". Conforme discutido na seção destinada à análise e discussão dos resultados, por vezes, o subjuntivo constitui uma servidão gramatical, para usar a terminologia de Câmara Jr. (1986) ou, nos termos de Bybee, Perkins e Pagliuca (1994), um modo subordinante, como nos contextos de orações causais e concessivas, que em geral apontam para uma situação dada como certa, mesmo com a presença do subjuntivo. Casos como esses põem em evidência um uso acionado por um gatilho sintático.

\section{0 uso variável do modo subjuntivo no PB}

Nesta seção, são apresentadas pesquisas conduzidas com dados do português brasileiro (PB) em três regiões do país: região Sul (PIMPÃO, 1999, 2012), região Sudeste (ALMEIDA, 2010) e região Nordeste (MEIRA, 2006; CARVALHO, 2007). Essas pesquisas não apresentam uniformidade com relação aos contextos de análise considerados e à perspectiva (se sincrônica ou diacrônica) (PIMPÃO; GÖRSKI, 2010), porém todas apresentam resultados para o tempo presente do subjuntivo ${ }^{5}$. Esses estudos tomam como referência os contextos previstos pelas gramáticas normativas como de uso do modo

${ }^{5}$ O uso variável do modo subjuntivo é investigado em outros estudos realizados a partir da análise de dados do português brasileiro, no entanto não apresentam resultados isoladamente para o tempo presente, razão pela qual não foram contemplados na revisão do fenômeno empreendida neste artigo. 
subjuntivo e investigam, a partir de dados reais, se esse modo foi empregado ou se, em seu lugar, o usuário empregou o indicativo. Ainda, controlam, de alguma forma, a projeção temporal futura, ao qual o subjuntivo parece estar associado, mais que a um valor de incerteza, conforme previsão da gramática normativa (BECHARA, 2006; CEGALLA, 2007; CUNHA; CINTRA, 2007). Também as pesquisas de Pimpão $(1999,2012)$ e de Almeida (2010) apresentam evidências de que o subjuntivo é empregado em contextos de certeza. Dessas pesquisas importam os resultados de variáveis que contribuem para os objetivos propostos inicialmente neste artigo ${ }^{6}$.

\subsection{0 uso variável do modo subjuntivo na região Sul}

Pimpão (1999), conjugando pressupostos teórico-metodológicos da Teoria da Variação e Mudança e do funcionalismo linguístico norteamericano de orientação givoniana, investiga o uso variável do presente do modo subjuntivo e do presente do modo indicativo em dados de fala de 36 informantes de Florianópolis/SC (Banco de Dados do Projeto VARSUL ${ }^{7}$ ). São cinco os contextos linguísticos analisados: orações substantivas, adverbiais e adjetivas, orações com o item talvez e pressuposição. Uma das variáveis controladas foi tempo-modalidade ${ }^{8}$, primeira a ser selecionada pelo pacote estatístico VARBRUL, reunindo os seguintes fatores: futuridade, incerteza, atemporalidade e pressuposição, ilustrados, respectivamente, a seguir.

(1) "Esse aqui, e o mais velho, por eles, eles QUEREM assim QUE o meu marido VOLTE, mas eu não quero não." (FLP 03, L0462) (PIMPÃO, 1999, p. 71)

\footnotetext{
${ }^{6}$ Para conhecimento da totalidade de variáveis linguísticas e extralinguísticas controladas nas pesquisas mencionadas neste artigo, o leitor encontrará a referência completa dos trabalhos ao final do texto. 7 mara informações acerca do Banco VARSUL, acessar o site www.varsul.org.br.

8 A noção de modalidade, embasada na literatura funcionalista essencialmente centrada em Givón, A noção de modalidade, embasada na literatura funcionalista esse
abarca noções de incerteza, de habitualidade e de pressuposição.
}

(2) “É, a minha diversão eram os bailes. Adorava baile. Ainda hoje adoro. Infelizmente, TALVEZ ESTEJA mais acomodado, porque, realmente, a gente vai perdendo o hábito. Mas no tempo dessa gurizada, eu não perdia um baile." (FLP 04, L0303) (PIMPÃO, 1999, p. 71)

(3) "Não gosto de ir ao cinema, teatro. Teatro assim quando é uma peça QUE te CHAMA atenção, que tu vês que está, né? fazendo propaganda, né? Aí eu gosto." (FLP 04, L0465) (PIMPÃO, 1999, p. 72)

(4) "Mas como eu estava falando, o filme que marcou assim QUE eu lembro que marcou mais, porque olha só, primeiro foi um filme de ficção científica que assim, mais bem feito na época, né?"9 (FLP 01, L0701) (PIMPÃO, 1999, p. 73)

O exemplo (1) ilustra um contexto de futuridade na consideração de que a volta do marido evidencia uma situação projetada para o futuro, podendo vir ou não a acontecer. A previsão é de que o traço de futuridade, associado à incerteza, constitua o ambiente favorável ao uso do subjuntivo. 0 trecho (2) ilustra o fator incerteza em um contexto marcado por uma situação não asseverada como verdadeira - talvez esteja acomodado -, porém sem projeção futura. Em (3), a atemporalidade se manifesta na apresentação de uma situação considerada habitual. No exemplo (4), que ilustra a pressuposição,

o conhecimento compartilhado ou a pressuposição da existência de um conhecimento compartilhado aproxima os participantes da atividade lingüística. Falante-ouvinte compartilham ou imaginam compartilhar as mesmas informações e, na atribuição de conhecimento, estão aptos a cancelar pressupostos derivados pragmaticamente (PIMPÃO, 1999, p. 73).

9 Os dados de (1) a (4) constituem exemplos ilustrativos de, respectivamente, oração substantiva, oração com o item talvez, oração adjetiva e pressuposição (PIMPÃO, 1999). Em trabalho posterior, Pimpão (2012) revê o termo pressuposição e, em substituição, adota oração parentética. 
Em (4), já antecipando uma possível intervenção por parte do entrevistador, o entrevistado, após afirmar o filme que mais marcou sua vida, relativiza essa informação, dizendo que eu lembro. Os fatores que compõem a variável tempo-modalidade estão apresentados na Tabela 1 , a seguir.

Tabela 1 - Atuação da variável tempo-modalidade sobre o uso do presente do subjuntivo (PIMPÃO, 1999, p. 73)

\begin{tabular}{lcc}
\hline \multicolumn{2}{c}{ Tempo-modalidade } \\
Fatores & Aplicação/Total & $\%$ \\
Futuridade & $106 / 128$ & 83 \\
Incerteza/atemporalidade/pressuposição & $81 / 191$ & 42 \\
Total & $187 / 319$ & 59 \\
\hline
\end{tabular}

Como pode ser observado, os três últimos fatores foram amalgamados em função da ausência de projeção futura e devido à proximidade do peso relativo constatada em rodadas estatísticas anteriores. "Na verdade, os amálgamas evidenciam a relevância do traço de futuridade como fator de diferenciação entre as variantes e não do traço de incerteza, conforme prevê a norma gramatical." (PIMPÃO, 1999, p. 126) A Tabela 1 contrasta casos em que uma situação é projetada para o futuro e casos em que essa projeção não se manifesta. De um total de 319 ocorrências, $83 \%$ de uso de subjuntivo está associado ao fator futuridade, conforme ilustrado em (1).

Pimpão (2012), dando continuidade ao estudo iniciado em sua dissertação de mestrado (PIMPÃO, 1999), amplia a amostra de análise de forma a incorporar dados de fala da cidade de Lages/SC (Banco de Dados do Projeto VARSUL), além de estender a pesquisa para uma abordagem diacrônica com base em cartas ao redator das cidades de Floria- nópolis e Lages. Novamente, são cinco os contextos linguísticos investigados: orações substantivas, adverbiais e adjetivas, orações com o item talvez e orações parentéticas (nomeada pressuposição em PIMPÃO, 1999).

Pimpão (2012) trata os dados de fala em dois momentos: primeiramente, para testar a importância estatística da cidade como uma varável independente, considera dados de 24 informantes de Florianópolis e 24 de Lages. Em um segundo momento, para testar a significância das variáveis idade e escolaridade, trabalha com dados de $44^{10}$ informantes de Florianópolis, amostra VARSUL/SC ampliada para abarcar falantes jovens e falantes universitários.

A primeira varável a obter relevância estatística nas rodadas com dados de ambas as cidades refere-se à projeção temporal da situação codificada, desdobrada em dois fatores: com projeção futura e sem projeção futura. A projeção futura manifesta-se quando a situação codificada na oração em que o subjuntivo ou o indicativo aparece for projetada ao futuro (cf. dado (5)). Se a situação codificada estiver espraiada entre passado, presente e futuro, estará instaurado um ambiente de projeção espraiada (cf. dado (6)) $)^{11}$. Os resultados apontam um percentual de $73 \%$ para o uso do presente do subjuntivo em contexto de projeção futura em Florianópolis, e de $88 \%$ para o mesmo contexto, em Lages, conforme ilustra a Tabela 2 a seguir.

${ }^{10} \mathrm{O}$ banco-base do VARSUL armazena 24 entrevistas da capital de cada estado da Região Sul, bem como de três cidades representativas de etnias em cada estado, estando composto por entrevistas com informantes entre 25 e 50 anos e acima de 50, compreendendo três níveis de escolaridade: primário, ginásio e colegial. 0 banco de Florianópolis está, no entanto, em expansão, e já reúne 12 entrevistas com informantes jovens e 8 com universitários.

${ }^{11} \mathrm{~A}$ codificação dos dados obedeceu à análise da situação em que o dado aparece, não à morfologia verbal. 
Tabela 2 - Atuação da variável projeção temporal sobre o uso do presente do subjuntivo (PIMPÃO, 2012, p. 226)

\begin{tabular}{lcccc}
\hline \multicolumn{4}{c}{ Projeção temporal da situação codificada } \\
Fatores & \multicolumn{2}{c}{ Florianópolis } & \multicolumn{2}{c}{ Lages } \\
\cline { 2 - 5 } & Aplicação/Total & $\%$ & Aplicação/Total & $\%$ \\
Projeção futura & $49 / 67$ & 73 & $48 / 54$ & 88 \\
Projeção espraiada & $87 / 183$ & 47 & $94 / 174$ & 54 \\
Total & $136 / 250$ & 54 & $142 / 228$ & 62 \\
\hline
\end{tabular}

Novamente a projeção futura desponta como contexto preferencial de uso do presente do subjuntivo. Vejamos dois exemplos.

(5) “É uma série de coisas que você tem no meio de um $\mathrm{CTG}^{12}$, assim até era bom vocês participarem um dia, PODE SER QUE vocês PARTICIPEM, então você vê que vai ser ótimo pra vocês." (PIMPÃO, 2012, p. 200)

(6) "eu sinto, assim, como se- A gente é espírita, quem não é espírita, TALVEZ não SENTE, não SABE dizer o que que sente. Sente, mas não sabe como identificar, né? os sonhos, a amizade pela pessoa." (PIMPÃO, 2012, p. 288)

Em (5), o informante se dirige ao entrevistador para convidá-lo a participar das atividades promovidas por um CTG. A participação é, então, projetada para o futuro, e, nesse sentido, a participação pode ou não vir a acontecer. Diferentemente, em (6), a situação não é projetada diretamente para o futuro, mas se espraia entre passado, presente e futuro, daí a noção de projeção espraiada. Nesse caso, o informante considera a percepção de uma pessoa que não é espírita. Essa pessoa, seja ela qual for, pode ter menos condições de identificar o que sente e de saber o que sente, justamente por não ser espírita.

${ }^{12}$ A sigla CTG remete a Centro de Tradições Gaúchas.
No conjunto de dados referentes às 44 entrevistas de Florianópolis, a variável projeção temporal da situação codificada não obteve relevância estatística. De qualquer forma, o percentual alcançado aproxima-se do encontrado nas 24 entrevistas da mesma cidade para o fator projeção futura $-76 \%-$, conforme Tabela 3 a seguir.

Tabela 3 - Atuação da variável projeção temporal sobre o uso do presente do subjuntivo (PIMPÃO, 2012, p. 271)

\begin{tabular}{lcc}
\hline & Projeção temporal da situação codificada & \\
Fatores & Aplicação/Total & $\%$ \\
\hline Projeção futura & $83 / 109$ & 76 \\
Projeção espraiada & $177 / 336$ & 52 \\
Total & $260 / 445$ & 58 \\
\hline
\end{tabular}

Na rodada com os dados diacrônicos, obtidos a partir de cartas ao redator, essa variável foi a terceira selecionada pelo programa Goldvarb em Florianópolis, e a primeira em Lages, com os respectivos percentuais para o fator projeção futura: 95\% e 98\%. Observa a Tabela 4.

Tabela 4 - Atuação da variável projeção temporal sobre o uso do presente do subjuntivo (PIMPÃO, 2012, p. 298)

\begin{tabular}{|c|c|c|c|c|}
\hline \multicolumn{5}{|c|}{ Projeção temporal da situação codificada } \\
\hline \multirow{2}{*}{ Fatores } & \multicolumn{2}{|c|}{ Florianópolis } & \multicolumn{2}{|c|}{ Lages } \\
\hline & Aplicação/Total & $\%$ & Aplicação/Total & $\%$ \\
\hline Projeção futura & $125 / 131$ & 95 & $161 / 164$ & 98 \\
\hline Projeção espraiada & $70 / 99$ & 70 & $71 / 105$ & 67 \\
\hline Total & $195 / 230$ & 84 & $232 / 269$ & 86 \\
\hline
\end{tabular}


(7) “COM QUANTO RECONHEÇA minha falta de recursos intellectuaes e de instrucção adquerida no seio da sociedade, porque vivo afastado della, tenho com tudo o arrojo de lhe pedir a inserção destas linhas no seu lido jornal (Jornal O Lageano de 10/06/1883)." (PIMPÃO, 2012, p. 313)

Em (7), o leitor, ao se dirigir ao redator do jornal, reconhece a falta de recursos intelectuais e de instrução adquirida, assumindo essas informações como verdadeiras, como certas. "O remetente antecipadamente se justifica a uma possível recusa na publicação de sua carta devido à falta de recursos intellectuaes $\boldsymbol{e}$ de instrucção adquerida."13 (PIMPÃO, 2012, p. 313).

\subsection{0 uso variável do modo subjuntivo na região Sudeste}

Na região Sudeste, Almeida (2010), conjugando pressupostos da Teoria da Variação e Mudança e do Funcionalismo Linguístico de vertente norte-americana, investiga o uso variável do presente e do imperfeito do subjuntivo em contexto de orações substantivas e de orações adverbiais concessivas. As amostras são compostas por textos escritos do século XIII ao século XX e por dados de fala do Rio de Janeiro (NURC e PEUL) e Salvador (NURC).

Na análise dos dados diacrônicos, Almeida (2010, p. 104) observa que, nos casos de orações substantivas, "o modo subjuntivo se mantém quando ocorre sob o escopo do traço de futuridade, uma vez que, nesse contexto, projeta a realização de eventos vindouros". A sensibilidade do subjuntivo à projeção futura também é atestada nas orações concessivas com ainda que, conforme ilustra a Tabela 5.

${ }^{13}$ Pimpão (2015) discute casos como os apresentados em (4) e (7) com base no cancelamento de inferências.
Tabela 5 - Atuação da variável tempo do evento sobre o uso do subjuntivo (ALMEIDA, 2010, p. 215)

\begin{tabular}{lcc}
\hline \multicolumn{2}{c}{ Tempo do evento em relação ao momento da enunciação } & \\
\hline Fatores & Aplicação/Total & $\%$ \\
Presente com ideia de futuridade & $34 / 39$ & 87 \\
Presente & $133 / 207$ & 64 \\
Passado & $43 / 111$ & 39 \\
Total & $210 / 375$ & 56 \\
\hline
\end{tabular}

De acordo com Almeida (2010, p. 208), o percentual de 87\% "confirma a hipótese de que a noção de futuridade contribui para a seleção do subjuntivo na oração subordinada", conforme ilustra o exemplo a seguir.

(8) "e a experiência o tem mostrado neste mesmo Estado do Maranhão, em que muitos governadores adquiriram grandes riquezas e nenhum dêles as logrou nem elas se lograram; nem há cousa adquirida nesta terra que permaneça, como os mesmos moradores dela confessam, nem AINDA QUE VÁ por diante, nem negócio que aproveite, nem navio que aqui se faça que tenha bom fim; porque tudo vai misturado com sangue dos pobres, que está sempre clamando ao céu." (ALMEIDA, 2010, p. 208)

Por oposição, admite a pesquisadora que, “à medida que o enunciador admite a hipótese ou incerteza de um determinado evento ocorrer, a proposição perde o traço de futuridade/obrigatoriedade, selecionando, assim, o modo indicativo" (ALMEIDA, 2010, p. 262).

Com relação às orações concessivas, Almeida (2010) apresenta ocorrências que conjugam uma situação atestada como real e o emprego do modo subjuntivo, conforme observado em (9).

(9) "POR MAIS QUE a minissaia FOSSE, que elas CONSIDERASSEM bonitas, eu acho que elas não tinham..." (ALMEIDA, 2010, p. 254) 


\subsection{O uso variável do modo subjuntivo na região Nordeste}

Na região Nordeste, Meira (2006), valendo-se da Teoria da Variação e Mudança e de pressupostos teóricos da Transmissão Linguística Irregular, analisa os três tempos do modo subjuntivo em contexto de orações substantivas e adjetivas. A amostra é constituída por 28 entrevistas com descendentes afro-brasileiros e pertence ao Acervo de Fala Vernácula do Português Afro-Brasileiro.

Dentre as variáveis independentes controladas no contexto de oração adjetiva, a localização temporal do evento expresso na oração relativa ${ }^{14}$ em relação ao momento da enunciação obtém a primeira colocação na seleção estatística. Os resultados são apresentados na Tabela 6.

Tabela 6 - Atuação da variável localização temporal sobre o uso do subjuntivo (MEIRA, 2006, p. 215)

\begin{tabular}{lcc}
\hline \multicolumn{2}{c}{ Localização temporal do evento expresso na oração relativa } \\
\hline Fatores & Aplicação/Total & $\%$ \\
\hline Posterior à elocução & $17 / 31$ & 61 \\
Simultaneamente à elocução & $09 / 38$ & 13 \\
Anterior à elocução & $12 / 66$ & 15 \\
Total & $38 / 135$ & 28 \\
\hline
\end{tabular}

Os resultados indicam a sensibilidade do modo subjuntivo à situação localizada após o momento da enunciação, decaindo consideravelmente quando o evento é simultâneo ou anterior à elocução. Ainda que a frequência total não seja expressiva, o percentual de $61 \%$ assinala um contexto

${ }^{14}$ Meira (2006) faz referência a orações relativas; Pimpão $(1999,2012)$, a orações adjetivas. Ao fazer referência às pesquisas, mantenho a terminologia adotada pela autora de cada trabalho. permeável ao subjuntivo. A seguir, o exemplo ilustra uma situação projetada para o futuro.

(10) "Quando a gente vai tem em quarqué um das casa. QUE Fô..." (MEIRA, 2006, p. 215)

Carvalho (2007), sob a perspectiva da Teoria da Variação e Mudança, investiga o uso variável do presente e do imperfeito do subjuntivo em orações substantivas. A amostra é constituída por dados de fala de 60 informantes da região do Cariri, microrregião localizada ao sul do estado do Ceará. Os dados fazem parte do Banco de Dados dos Estudos de Língua Oral do Ceará.

Tomando como parâmetro o grupo de fatores tempo-modalidade (PIMPÃO, 1999), Carvalho (2007) tenciona observar o comportamento das noções de temporalidade e modalidade. A variável Modalidade, cujos resultados são apresentados na Tabela 7 , foi o terceiro grupo de fatores a obter relevância estatística.

Tabela 7 - Atuação da variável modalidade sobre o uso do presente do subjuntivo (CARVALHO, 2007, p. 106)

\begin{tabular}{lcc}
\hline \multicolumn{2}{c}{ Modalidade* $^{*}$} & \\
Fatores & Aplicação/Total & $\%$ \\
Futuridade & $25 / 26$ & 96 \\
Dicendi & $03 / 17$ & 18 \\
Incerteza/avaliação** & $41 / 220$ & 19 \\
Certeza & $01 / 23$ & 04 \\
Total & $70 / 286$ & 24 \\
\hline
\end{tabular}

* De acordo com Carvalho (2007, p. 79), o grupo de fatores intitulado modalidade "foi pensado a partir da proposta de Pimpão (1999).

** Para Carvalho (2007, p. 79-80), o fator incerteza/avaliação se manifesta quando "o falante avalia, opina através de construções que apresentem verbos na matriz cujo traço semântico não assevera fatos, mas auxiliam na expressão da posiç̃ão do falante em relac̃ã à proposiç̃̃o enunciada". Há inclusive, casos, mas auxiliam na expressão da posição do falante em relação à proposição enunciada". Há, inclusive, casos com o verbo achar na oração matriz e subjuntivo na oração subordinada: "Eu acho que seja a falta, a falta de (CARVALHO, 2007, p. 80) 
Destaca-se a frequência total para o fator incerteza/avaliação. Do total de 220 ocorrências, 170 ocorrem com o verbo achar, contexto de incerteza e ambiente preferencial de uso do presente do indicativo. Mesmo com pouca expressão em termos frequenciais, o uso do presente do subjuntivo em contexto de futuridade atinge um percentual elevado, resultado que se alinha aos encontrados nas pesquisas anteriores. Um exemplo para ilustrar o fator futuridade pode ser observado em (11).

(11) "Eu TORÇO e PRETENDO que a escola pública daqui a quinze anos ela SEJA resgatada, ESTEJA melhorada... vai ser bem eu não preciso colocar os meus filho em escola particular." (CARVALHO, 2007, p. 79)

Exemplos como o ilustrado em (11), apresentam situações em que a futuridade se manifesta. Em casos como esse, o informante projeta para o futuro desejos, anseios, ideias.

A correlação entre o uso do modo subjuntivo e a projeção futura foi destaque nas pesquisas apresentadas nesta seção: Pimpão (1999), Meira (2006), Carvalho (2007), Almeida (2010) e Pimpão (2012) para dados do português do Brasil. Para encerrar esta seção, destaco uma pesquisa realizada com dados do espanhol, justamente por contribuir com evidências acerca da sensibilidade do modo subjuntivo a contextos de projeção futura. Poplack e Pousada (1981) conduzem um estudo sobre o sistema verbal do espanhol de Porto Rico em situação de contato com o inglês dos Estados Unidos. Nessa pesquisa, o presente do subjuntivo constitui a forma verbal simples mais frequente, "incluída nessa categoria devido a sua natureza imperfectiva e também por ser orientada para o futuro" (POPLACK; POUSADA, 1981, p. 221).

\section{Projeção futura e modo subjuntivo}

Tanto a Sociolinguística Quantitativa quanto o funcionalismo linguístico de orientação givoniana não concebem a língua dissociada de seu uso, sendo, portanto, heterogênea, maleável, variável. Conforme Tavares e Görski (2012), a sociolinguística não se distancia tanto do funcionalismo. É na articulação de pressupostos teórico-metodológicos da sociolinguística variacionista e do funcionalismo linguístico norte-americano, embasado na literatura givoniana, mas também no que se tem denominado linguística baseada no uso, que surge uma orientação direcionada ao estudo da variação e da mudança, denominada sociofuncionalismo.

Quatro das cinco pesquisas referidas neste artigo conjugam pressupostos da Teoria da Variação e Mudança e do funcionalismo linguístico norteamericano. A pesquisa de Weiner e Labov (1983 [1977]) sobre a passiva sem agente, ao tratar de um fenômeno sintático, abre um precedente para expandir a aplicação da teoria para outros níveis de análise. Claro está que essa questão não é pacífica. Iniciada no conhecido debate entre Lavandera (1977) e Labov (1978), a extensão da regra variável para além da morfologia permitiu uma possibilidade de conjugação teórica, o Sociofuncionalismo (TAVARES, GÖRSKI, 2013).

Desse funcionalismo, para fins deste trabalho, importa considerar a modalidade. Complexa categoria gramatical, a modalidade integra o TAM - tempo, aspecto e modalidade -, podendo ser conceituada como "opinião ou atitude do falante" (PALMER, 1986, p. 2), definição emprestada de Lyons (1977) e que aparece em Bybee, Perkins e Pagliuca (1994) e em Givón (1995, 2001). Givón (1995, 2001), no entanto, reinterpreta a definição baseada em Lyons (1977), deslocando-a para o eixo comunicativo, para o discurso multiproposicional. Assim definida, a modalidade é uma onipresente nas línguas, posto que os usuários, a todo momento, emitem juízos de valor acerca do que enunciam (cf. BYBEE; FLEISCHMANN, 1995).

Givón (2005, p. 149) ainda complementa a definição de modalidade: "a atitude do falante não é apenas - nem principalmente - sobre a proposição 
propriamente dita, mas sim sobre a atitude do ouvinte em relação à proposição assim como em relação ao falante". A consideração do fator pragmático presente na comunicação recebe realce nessa obra. Orações adverbiais concessivas e causais ilustram a relação falante-ouvinte na medida em que manifestam um cancelamento de uma inferência atribuída pelo falante ao ouvinte (cf. (7), por exemplo).

Observemos mais dois exemplos.

(12) "Ele dorme à tarde, de manhã ele faz alguma coisa. Ele é muito parecido com o pai dele, né? gosta de cuidar do jardim, né? NÃO É QUE ele SEJA caprichoso, ele não é nem um pouco, mas ele gosta de estar mexendo para cá, para lá, assim." (PIMPÃO, 1999, p. 101)

(13) “Hoje já não tanto, porque o que a gente tem assistido pela televisão, o problema de assassinato no Rio de Janeiro, realmente dá até medo de sair de casa, EMBORA nós TENHAMOS, resguardadas as proporções, também aqui em Florianópolis uma cidade pacata como a nossa, que vêm acontecendo crimes bárbaros, aí, né?" (PIMPÃO, 1999, p. 106)

Em (12), ao afirmar "não é que ele seja caprichoso", o informante orienta o entrevistador a não derivar tal inferência a partir das informações anteriores: o filho de manhã faz alguma coisa e gosta de cuidar do jardim. Ou seja, a oração causal iniciada por não é que indica que uma possível inferência gerada pelo contexto anterior e antecipadamente atribuída ao entrevistador não deve ser por este considerada. Da mesma forma, em (13), o informante assegura que, em Florianópolis, ocorrem crimes assim como no Rio de Janeiro. O subjuntivo, considerado pelas gramáticas normativas o modo da incerteza, ocorre em contextos de certeza. Não há dúvida de que um valor de certeza está assinalado em (12) - o entrevistador não deve considerar o filho caprichoso e em (13) - há situações de crime/violência em Florianópolis (PIMPÃO, 2015).
Esses casos parecem constituir o que Câmara Jr. (1986) denomina de servidão gramatical, ou, nos termos de Bybee, Perkins e Pagliuca (1994), modo subordinante. Contextos como esses são discutidos por Pimpão (2012, 2015). Pimpão (2015, p. 388) analisa especificamente contextos de orações causais (12) e de orações concessivas (13), caracterizados pela "propriedade de corrigir pressuposições atribuídas ao ouvinte ou por ele expressadas".

Como exemplo da atitude do falante em relação à proposição, é possível ilustrar com todas as ocorrências de projeção futura. Nesses casos, a atenção está na projeção de uma determinada situação para um tempo posterior ao momento da comunicação. Para Givón $(1995,2001)$, o denominador comum para o emprego do modo subjuntivo é a incerteza epistêmica, que se manifesta em dois eixos: o da modalidade deôntica (eixo do desejo, da obrigação) e o da modalidade epistêmica (eixo do conhecimento). Um dos aspectos diferenciais reside na noção de futuridade, fortemente associado ao deôntico. Se pensarmos em um continuum de modalidade, o subjuntivo está mais propenso a aparecer quando futuridade e, por conseguinte, incerteza, estiverem presentes (PIMPÃO, 1999, 2012).

\section{Palavras finais}

Com base nos resultados das pesquisas sociolinguísticas apresentadas neste artigo, o modo subjuntivo não pode ser considerado apenas o modo da incerteza, conforme preveem as gramáticas normativas. Os resultados retomados e discutidos indicam que o modo subjuntivo deve ser considerado como modo da incerteza apenas de forma secundária, por implicação do valor de projeção futura, que se mostrou uniforme nos estudos com dados de fala e de escrita de informantes das regiões Sul, Sudeste e Nordeste. Os estudos destacados neste artigo demonstram a sensibilidade do uso desse 
modo verbal a contextos em que uma determinada situação é projetada para o futuro. $\mathrm{O}$ ambiente de projeção futura, portanto, constitui o contexto preferencial para seu emprego.

Ademais, esse modo verbal ainda pode ser empregado em contextos de pressuposição, que se aproximam mais da certeza, distanciando-se da incerteza, como os casos com os conectores concessivos e os conectores causais. Nesses casos, especialmente sob o escopo do conector embora, o subjuntivo parece ser empregado devido a uma servidão gramatical (CÂMARA JR., 1986), constituindo um modo subordinante (BYBEE; PERKINS; PAGLIUCA, 1994) (PIMPÃO, 2015). Casos como esses, ainda que muito específicos, constituem indícios de que o subjuntivo não pode ser considerado o modo da incerteza, conforme defendem as gramáticas normativas.

De forma geral, o subjuntivo pode ser associado à incerteza, em decorrência da projeção futura, que ganhou destaque nas pesquisas aqui referidas. No entanto, da mesma forma, também constitui o modo da certeza, ainda que nos contextos específicos de orações concessivas, especialmente as introduzidas pelo conector embora e as orações causais.

\section{Referências}

ALMEIDA, Erica Sousa de. Variação de uso do subjuntivo em estruturas subordinadas: do século XIII ao XX. 2010. 294f. Tese (Doutorado em Letras Vernáculas) - Faculdade de Letras, Universidade Federal do Rio de Janeiro, Rio de Janeiro, 2010.

BARBOZA, Joaquim Soares. Grammatica philosophica da lingua portugueza. Lisboa: Tipographia da Académia Real das Sciencias, 1830

BARROS, João de. Gramática da língua portuguesa. Organizado por José Pedro Machado. 3. ed. 1957 [1540].

BECHARA, Evanildo. Moderna gramática portuguesa. 37. ed. rev. e amp. Rio de Janeiro: Lucerna, 2006
BYBEE, Joan; FLEISCHMAN, Suzanne. Modality in grammar and discourse. Amsterdam/ Philadelphia: John Benjamins, 1995.

BYBEE, Joan; PERKINS, Revere; PAGLIUCA, William. The evolution of grammar: tense, aspect, and modality in the languages of the world. Chicago: The University of Chicago Press, 1994.

CÂMARA JR., Joaquim Mattoso. Dicionário de linguística e gramática. 13. ed. Petrópolis: Vozes, 1986.

História e estrutura da língua portuguesa. 2. ed. Rio de Janeiro: Padrão, 1979.

Princípios de linguística geral. 4. ed. Rio de Janeiro: Acadêmica, 1974.

CARVALHO, Hebe Macedo de. A alternância indicativo/subjuntivo nas orações substantivas em função dos tempos verbais presente e imperfeito na língua falada do Cariri. 2007.158fl. Tese (Doutorado em Linguística) - Departamento de Letras Vernáculas, Universidade Federal do Ceará, Fortaleza, 2007.

CEGALLA, Domingos Paschoal. Novíssima gramática da língua portuguesa. 46. ed. São Paulo: Companhia Editora Nacional, 2007.

CUNHA, Celso. Gramática da língua portuguesa. Rio de Janeiro: FAE, 1992.

CUNHA, Celso; CINTRA, Lindley. Nova gramática do português contemporâneo. 4. ed. Rio de Janeiro: Lexikon Editora Digital, 2007.

GIVÓN, Talmy. Bio-linguistics. Amsterdam/Philadelphia: John Benjamins, 2002.

Context as other minds: the pragmatics of sociality, cognition and communication. Amsterdam/Philadelphia: John Benjamins, 2005

Functionalism and grammar. Amsterdam/Philadelphia: John Benjamins, 1995.

LABOV, William. Where does the linguistic variable stop? A response to Beatriz Lavandera. Working Papers in Sociolinguistics, 44, p. 1-17. 1978.

LAVANDERA, Beatriz. Where does the sociolinguistic variable stop? Paper presented at Linguistic Society of América Meeting, Chicago, p. 1-18.1977.

LYONS, John. Semantics. Vol II. Cambridge: Cambridge University Press, 1977.

MEIRA, Vivian. $O$ uso do modo subjuntivo em orações relativas e completivas no português afro-brasileiro. 2006. 317f. Dissertação (Mestrado em Letras e Linguística) - Instituto de Letras, Universidade Federal da Bahia, Salvador, 2006.

MATTOS E SILVA, Rosa Virgínia. O português arcaico: fonologia, morfologia e sintaxe. São Paulo: Contexto, 2006 
PALMER, Frank. Mood and modality. Cambridge: Cambridge University Press, 1986. PERINI, Mário. Gramática descritiva do português. São Paulo: Ática, 1996.

. Gramática do português brasileiro. São Paulo: Parábola, 2010.

Princípios de linguística descritiva: introdução ao pensamento gramatical. São Paulo: Parábola, 2006

PIMPÃO, Tatiana Schwochow. Presente do subjuntivo e presente do indicativo: um encontro na história. Working Papers em Linguística, Florianópolis, v. 10, n 1, p. 1-16, jan. jun. 2009.

Pressuposição e a variação no presente do modo subjuntivo. In: Revista Letrônica, Porto Alegre, v. 8, n 2, p. 376-390, jul. dez. 2015.

Variação no presente do modo subjuntivo: uma abordagem discursivo-pragmática. 1999. 129 fl. Dissertação (Mestrado em Linguística) - Centro de Comunicação e Expressão, Universidade Federal de Santa Catarina, Florianópolis, 1999.

Uso variável do presente do modo subjuntivo: uma análise de amostras de fala e escrita das cidades de Florianópolis e Lages nos séculos XIX e XX. 2012. $350 \mathrm{fl}$. Tese (Doutorado em Linguística) - Centro de Comunicação e Expressão, Universidade Federal de Santa Catarina, Florianópolis, 2012

PIMPÃO, Tatiana Schwochow; GÖRSKI, Edair Maria. Interpretação qualitativa de resultados quantitativos: uma análise do processo metodológico na comparação de diferentes pesquisas. Working Papers em Linguística, Florianópolis, n 1, p. 71-81, 2010.

POPLACK, Shana; POUSADA, Alicia. No case for convergence: the Puerto Rican Spanish verb system in a language contact situation. In: KELLER, G.; FISHMAN, J. (Ed.). Bilingual Education for Hispanic Students in the United States. New York: Columbia University Teacher's College Press, 1981. p. 206-236.

Said ALI, Manuel. Gramática histórica da língua portuguêsa. 7. ed. São Paulo: Melhoramentos, 1971.

SILVA-CORVALÁN, Carmen. The gradual loss of mood distinctions in Los Angeles Spanish. Language Variation and Change, 6(3), p. 255-272, 1994. https://doi.org/10.1017/ S095439450000168X

TAVARES, Maria Alice; GÖRSKI, Edair Maria. Bases teórico-metodológicas para uma interface sociofuncionalista. In: XXVII Encontro da ANPOLL. Rio de Janeiro, 2012.
Reflexões teórico-metodológicas a respeito de uma interface sociofuncionalista. In: Revista do GELNE, Natal, v. 15, n. esp., p. 79-101, 2013.

WEINER, Judith; LABOV, William. Constrains on the agentless passive. Journal of Linguistics, v. 19, n. 1, p. 29-58, 1983 [1977].

Recebido em 08/01/2017

Aceito em 02/06/2017. 